\title{
BMG Global Health How men who have sex with men experience HIV health services in Kampala, Uganda
}

\author{
Rachel King (D) , ${ }^{1}$ Zubayiri Sebyala, ${ }^{2}$ Moses Ogwal, ${ }^{2}$ George Aluzimbi, ${ }^{3}$
} Rose Apondi, ${ }^{3}$ Steven Reynolds, ${ }^{4,5}$ Patrick Sullivan, ${ }^{6}$ Wolfgang Hladik ${ }^{7}$

To cite: King R, Sebyala Z, Ogwal $\mathrm{M}$, et al. How men who have sex with men experience HIV health services in Kampala, Uganda. BMJ Global Health 2020;5:e001901. doi:10.1136/ bmjgh-2019-001901

Handling editor Stephanie M Topp

Received 12 August 2019 Revised 10 March 2020 Accepted 15 March 2020

\section{Check for updates}

\section{Author(s) (or their} employer(s)) 2020. Re-use permitted under CC BY-NC. No commercial re-use. See rights and permissions. Published by BMJ.

For numbered affiliations see end of article.

Correspondence to Dr Rachel King; rachel.king@ucsf.edu

\section{ABSTRACT}

In sub-Saharan Africa, men who have sex with men (MSM) are socially, largely hidden and face disproportionate risk for HIV infection. Attention to HIV epidemics among MSM in Uganda and elsewhere in sub-Saharan Africa has been obscured by repressive governmental policies, criminalisation, stigma and the lack of basic epidemiological data describing these epidemics. In this paper, we aim to explore healthcare access, experiences with HIV prevention services and structural barriers to using healthcare services in order to inform the acceptability of a combination HIV prevention package of services for men who have sex with men in Uganda. We held focus group discussions (FGDs) with both MSM and healthcare providers in Kampala, Uganda, to explore access to services and to inform prevention and care. Participants were recruited through theoretical sampling with criteria based on ability to answer the research questions. Descriptive thematic coding was used to analyse the FGD data. We described MSM experiences, both negative and positive, as they engaged with health services. Our findings showed that socio-structural factors, mediated by psychological and relational factors impacted MSM engagement in care. The socio-structural factors such as stigma, homophobia and policy issues emerged strongly as did the mediating factors such as relations with specific health staff and a social support structure. A combination intervention addressing structural, social and psychological barriers could have an impact even in the precarious policy environment where this study was conducted.

\section{INTRODUCTION}

In sub-Saharan Africa, men who have sex with men (MSM) are a largely hidden population with disproportionate risk for HIV infection. ${ }^{1-5}$ Attention to HIV epidemics among MSM in sub-Saharan Africa has been obscured by repressive governmental policies, criminalisation, stigma and the lack of basic epidemiological data describing these epidemics. ${ }^{6}$ Despite more recent research on HIV among MSM in Africa and their relationships to the generalised epidemics within which they exist, HIV healthcare access has been largely overlooked

\section{Key questions}

What is already known?

- It is increasingly clear that men who have sex with men (MSM) have a significantly greater disease burden than men in the general population.

What are the new findings?

- Socio-structural factors, mediated by psychological and relational factors impact MSM engagement in care. Stigma, homophobia and policy issues emerged strongly as did the mediating factors such as relations with specific health staff and a social support structure.

What do the new findings imply?

- A combination intervention addressing structural, social and psychological barriers could have an impact even in the precarious policy environment where this study was conducted.

by national HIV prevention policies, prevention service providers and the donor and the academic communities. ${ }^{78}$ The understanding of MSM in African communities, their social and sexual lives, health seeking behaviours and the multiple vulnerabilities and risks associated with their sexual behaviours in African contexts is important when investigating how HIV impacts this group. ${ }^{9}$ Same sex behaviour among men and HIV have been associated since early in the history of $\mathrm{HIV},{ }^{10}$ yet 35 years into the epidemic, male homosexual behaviour in relation to HIV has still been little studied in Africa. As more studies measure HIV infection in sub-Saharan Africa, it is becoming clear that MSM have a considerably greater disease burden than men in the general population. ${ }^{10-17}$

The growing literature on HIV and MSM in Africa, has found that higher risk sexual behaviour has been associated with trust in sexual partners, ${ }^{18}$ having partners younger than 18 years and not having had experience with HIV prevention programmes dedicated 
to MSM. ${ }^{19}$ A study on MSM risk in Mombasa, Nairobi and Dakar, described inconsistent condom use and multiple concurrent partners as normative behaviours. ${ }^{20}$ Higher risk behaviour has also been associated with depression among MSM in South Africa. ${ }^{21}$

Recently, some studies in sub-Saharan Africa have reported high levels of stigma, discrimination and violence, with even higher levels reported among some subgroups within MSM, such as male sex workers. ${ }^{20} 22-24$ Stigma has played a role in health seeking behaviour where MSM with higher perceived stigma were less likely to pursue healthcare and have trouble disclosing their sexual orientation to healthcare providers. ${ }^{25}$

In Uganda, as in many countries of sub-Saharan Africa, ${ }^{26}$ the law introduced in 2009 and passed in 2014, termed 'the gay bill', criminalises homosexual behaviour (Section 140, 141 and 143 Penal Code) and therefore makes it complicated for the Ministry of Health staff members to promote prevention or care programmes tailored to MSM and for MSM to access services. Though there has been limited research on MSM in Uganda, in 2007 Kajubi et al conducted a respondent driven sampling (RDS) survey among 228 MSM in Kampala and found in her sample that MSM were a heterogeneous, highly marginalised and stigmatised population, had high levels of risk behaviour and limited risk perception. ${ }^{1314}$ In 2008/2009, the Crane Survey, our parent study, using RDS, was the first to perform HIV testing among MSM survey respondents for HIV and other sexually transmitted infections. ${ }^{127}$ Full description of the Crane Survey, have been described previously. ${ }^{127}$ Briefly, the Crane Survey found that MSM in Kampala are at markedly higher risk for HIV than the general adult male population and that MSM reporting a lifetime history of homophobic abuse are at increased risk of being HIV infected. ${ }^{127}$ Population estimates were adjusted for the non-random sampling frame using RDSAT and Stata. ${ }^{1}$ The median age of 300 MSM was 25 years. Overall, HIV prevalence was $13.7 \%$ (95\% CI $7.9 \%$ to $20.1 \%$ ), and was higher among MSM $>=25$ years $(22.4 \%)$ than among MSM aged 18 to 24 years $(3.9 \%$, OR $5.69,95 \%$ CI 2.02 to 16.02$).{ }^{128}$ In this paper, we aimed to explore healthcare access, experiences with HIV prevention services, structural barriers to using healthcare services to inform the acceptability of a combination HIV prevention package of services for men who have sex with men in Uganda.

\section{METHODS}

\section{Qualitative design and sampling}

A theoretical sampling strategy was used ${ }^{29}$ for the qualitative substudy that would yield a purposively-selected sample of health workers and MSM.

Our study aimed to survey 70 MSM and 30 HIV service providers who lived and worked in Kampala, Uganda, to develop future HIV prevention strategies for MSM. The first objective of the study was to collect qualitative information from MSM about basic patterns of behaviours, perceptions of structural barriers to HIV prevention, healthcare access challenges, uptake of HIV prevention services and possible HIV prevention strategies. Objective 2 was to collect qualitative information from HIV service providers to assess existing services and provide insight on what is needed to make them more effective for MSM. Objective 3 was to collect information from MSM about sexual identity, social network composition, behavioural bisexuality, sexual practices, incarceration, relationship patterns, future prevention strategies and association with MSM support groups. We report here on perceptions and experiences of MSM and healthcare providers on access to HIV services.

\section{Participants and setting}

Two groups of participants were selected for focus group discussions (FGDs): HIV service providers and MSM. Potential participants were screened and; eligible participants were invited to attend an interview. On arrival at the study office, participants completed informed consent and screening questionnaires.

For HIV service providers to be eligible to participate in the focus groups, they had to have been employed at established clinics or medical centres in Kampala. HIV counsellors, nurses, clinical managers, social workers and clinicians were included in the discussions. Two groups of healthcare providers were included; those that serve the general public and providers known to be friendly towards MSM. There were a total of six FGDs conducted, with 10 participants each; three with MSM and three with healthcare providers.

Criteria for enrolment for MSM included being born male, being 18 years of age or older, residing in greater Kampala and able to converse in English (FGD), or, for in depth interview (IDI), English or Luganda. For HIV service providers, enrolment criteria included employment as HIV service providers at established clinics or medical centres (serving either the general public or MSM patients) in Kampala as HIV counsellors, nurses, clinical managers, social workers or clinicians. Sampling of healthcare providers was purposive; candidate MSM participants were identified through snowball sampling.

The focus group discussions were conducted in confidential rooms at the Crane Survey offices. In order to protect the confidentiality and safety of participants, the study office itself was located in an accessible area of central Kampala and not identifiable to the general public as a place frequented specifically by MSM.

All participants, received UgS (Ugandan shilling) 10 000 (US\$4.00) compensation as a transport reimbursement as was current practice for all Crane studies. The study took place between January 2016 and March 2016.

\section{Patient and public involvement}

Previous interaction with patients' in the Crane Survey where they shared some of their priorities, experiences and preferences helped to guide the development of the research questions and measures. Patients were not 
directly involved in study design but they were directly engaged in recruitment of study participants. In other Crane studies, we have brought study participants together to discuss and validate preliminary results. The same will be done for these results.

\section{Data collection and analysis}

MSM and healthcare providers formed separate focus group discussions. Initial questions included how MSM perceived their experiences with healthcare facilities; the comfort level for receiving HIV prevention services; perceived community concerns for MSM-related health outcomes, specifically HIV; concerns about the risk of HIV infection; HIV prevention strategies that MSM employ; interest in possible packages of care; barriers to HIV preventions and membership in MSM community based organisations.

For healthcare providers, questions included probing the comfort level administering HIV prevention services to MSM, perceived quality of training for providing services to MSM, experiences with MSM at the healthcare facilities, impact of the Anti-Homosexuality Act on healthcare services for MSM, community perceptions for health needs and outcomes of MSM, perceived strategies MSM use for HIV prevention as well as barriers for the same, interest in possible packages of care for MSM.

Two FGD facilitators were university-trained social scientists who received additional in-depth training for the study including: rapport building, interviewing/ facilitating techniques and use of the qualitative guides. Many discussions were held before and during the study regarding the sensitive nature of homosexuality in Uganda and how that may affect the research as well as the safety of staff and participants. The facilitators had more than 5 years of experience working with MSM in Uganda by the time of the data collection for this study. Use of FGDs allows facilitators to study people in a more natural setting than a one-to-one interview. They can be used for gaining access to various cultural and social groups, especially ones who are marginalised. FGDs were conducted by a facilitator and a note taker; conducted in Luganda and audio recorded. All transcripts were transcribed and translated into English by one of the two facilitators. An analysis team consisting of the social scientists who interviewed participants and three additional senior social scientists coded transcripts and met to agree on relevant themes. Analysis guidelines that included three distinct stages: theme development, theme validation and code use were used as the primary analytic strategy for thematic coding with an emphasis on descriptive versus interpretive themes. ${ }^{30}$ After reading two transcripts, the analysis team members collaboratively developed a codebook of themes based on the interview topics as well as those emerging from the data. Two more transcripts were then reviewed to include additional topic areas and themes. This process was repeated until a sample of 12 transcripts had been reviewed and the codebook reached a stage where no new themes or topic areas emerged. To ensure
Table 1 MSM participant characteristics $(n=40)$

Number of participants

(\%)

\begin{tabular}{|lcc|}
\hline Age & Mean age=22 years & \\
\hline Education & & 5 \\
\hline Primary & 2 & 70 \\
\hline Secondary & 28 & 25 \\
\hline Tertiary & 10 & \\
\hline Employment* & & 59 \\
\hline Unemployed & 23 & 20.5 \\
\hline Part-time & 8 & 20.5 \\
\hline Full-time & 8 & \\
Relationship status & \\
\hline Single & & 54 \\
\hline Dating & 21 & 38 \\
\hline Partnered & 15 & 5 \\
\hline Married & 2 & 3 \\
\hline Sexual preference* & 1 & \\
\hline Homosexual & 24 & 62 \\
\hline Bisexual & 13 & 33 \\
\hline Transgender† & 2 & 5 \\
\hline
\end{tabular}

*One missing.

†Self-identified.

MSM, men who have sex with men.

inter-rater consistency, the analysis team compared their individual coding of the same transcripts. All transcripts were then coded using the final version of the codebook and merged using NVivo software before themes were summarised across respondents. Analysis focussed on identifying the dominant and the range of explanations and comparisons across clients stratified by type of respondent. Multiple interactive discussions were held with the analysis team and senior researchers to validate data interpretations and resolve any interpretation discrepancies.

The study was approved by the Institutional Review Boards of the Uganda National Council on Science and Technology, Entebbe, Uganda, and the Uganda Virus Research Institute, Entebbe, Uganda. It was also reviewed in accordance with the Centers for Disease Control and Prevention (CDC), Atlanta, Georgia, USA, human research protection procedures, and was determined to be research, but CDC investigators did not interact with human subjects, nor access identifiable data or specimens for research purposes. All clients provided written informed consent for participating both in the main survey and separately for the qualitative interview.

\section{RESULTS}

Table 1 reports the demographics of the MSM participants. Participants' mean age was 22 years; most $(70 \%)$ had some secondary education and most were 
unemployed and single. Our participants both identified as homosexual (62\%) and bisexual (33\%).

\section{Socio-structural and personal barriers}

Results are reported according to subsections based on an emergent explanatory model. Some of the participants, both healthcare providers and MSM, narrated a model based on their experiences and explanations, which included elements related to policy, personal, social, cultural and environmental context.

\section{Policy level - 'The gay bill'}

The fear that surrounded the signing of the bill by the president of Uganda (Section 140, 141 and 143 Penal Code) instilled a great degree of fear in the MSM community. The bill was introduced in October of 2009 and was called 'No. 18, the Anti-Homosexuality Bill' by David Bahati, a member of Uganda's parliament. The Bill's aim was to consolidate a legislation to secure traditional family values by outlawing '(i) any form of sexual relations between persons of the same sex; and (ii) the promotion or recognition of such sexual relations'. On $24^{\text {th }}$ February 2014, the bill was signed into law by Ugandan president Yoweri Museveni.

Participants explained that they believed they could easily be arrested if they went to most of the health facilities in Kampala and that there were very few that they trusted. One participant even noted that he would travel from Entebbe (about $40 \mathrm{KM}$ ) to attend one trusted facility in Kampala.

The gay bill that was signed by the president of Uganda into law scared the boys. So, there is a lot of fear among MSM as they think that they can be easily arrested from those health facilities. (FGD-MSM)

Healthcare providers echoed the same sentiments noting that MSM believed that they could be detained at health facilities.

They might go to the facility and in the end, get imprisoned. The government in one way or the other hinders HIV prevention to MSM. (FGD-HCP)

\section{Discrimination in the community and the healthcare setting}

In addition to the policy environment, culturally and religiously, homophobia remains ingrained in the fabric of society in Kampala. Healthcare professionals (HCPs) described the prevalent norm at multiple levels of the family, health services and community.

These things like MSM are not accepted by culture. It is not accepted in the community because you will be a disgrace that means that you will also be a disgrace in your family. Your people will never understand you. And that means that whatever you are going to do, you will do it in secret you cannot want anyone to know. (FGD-HCP)

You can't say, 'I am going with my partner to the health facility' ... Nobody will ever understand it because it will always be evil. So, whenever something is unacceptable you do it by yourself. Find means of solving your problems. That makes it very difficult for them to have someone to give them these services. They cannot come out in the open everyone despises their kind of lifestyle, (FGD-HCP)

MSM described poor quality HIV service delivery including being given expired medication or being denied medication and reported healthcare staff claiming medication stock outs when the participant claimed that there was evidence showing medication in stock. In addition, participants reported experiencing breaches in their medical confidentiality and rude healthcare workers, and one participant narrated that he was denied service. Some of these constraints have been noted in the general population, but the degree experienced by MSM was perceived by participants as homophobia.

...even those centres which are friendly, supply expired drugs but... you feel that you really need that medicine. (FGD-MSM)

Being expired is one issue but when guys go there... someone goes there and the doctor prescribes treatment for him, he goes to the pharmacist and he is given less medicine or he is told that it is out of stock when in the actual sense it is available. (FGD-MSM)

Breaches of confidentiality were described by multiple participants and resulted in considerable discomfort to men when accessing HIV prevention and care.

Because you may find someone... infected with HIV. When the time comes for them to get their drugs, the pharmacist stands and shouts out a name. Come and get your medicine. Which type of medicine do you take? (FGD-MSM)

Can you imagine someone saying that when everyone is looking at you? In that case I become scared and fear to present myself to get my treatment... He came and the pharmacist asked him what type of drugs he was shifted to because the one he was taking wasn't helping him. Can you imagine when we were all there seated and some of us didn't know that he was positive. (FGD-MSM)

For those (health workers) who have not been oriented they can make someone a tourist attraction. They ask all their colleagues to come and see this one who has sex with men... most of the time they call some people and form like a crowd. (FGD-MSM)

One health provider narrated a conversation with a colleague who described a MSM patient as psychotic by the fact that the patient was gay. The colleague would not treat the patient and instead referred him for treatment of mental illness.

A woman and a man should behave like this. So, the moment you behave what the culture doesn't allow then you are thrown out. Even the community itself will start attacking you... If someone came and told others that you see that group... over there are MSM. People can opt to burn them without the government doing anything. Being homophobic affects HIV prevention among MSM. (FGD-HCP) 
Many participants simply stated that they do not access health services in many facilities because the staff are 'harsh', 'rude' or 'homophobic'. They reported preferring to self-medicate rather than risk potential social harm at the health facility.

I had experienced an infection and I failed to go to any public health centre for treatment simply because the workers in those places are homophobic. (FGD-MSM)

Participants described how, in Kampala, the health facilities where MSM feel comfortable were insufficient. They noted not feeling safe describing their sexual behaviour or health problems and having to pay for services they expected should be free.

\begin{abstract}
The health services which were given to the LGBTI were very few. There was no friendly health service where you could go and be open with the anal infection, maybe gonorrhoea and whatever to someone anywhere (FGD-MSM)

I remember there was a clinic and there was a doctor who used to help us. But when you go there you had to pay something. There was no facility where you had to refer somebody that this is a friendly clinic you go and meet so and so. People used to dig into their pockets for health services. (FGD-MSM)
\end{abstract}

\section{Social, psychological and structural moderating factors}

We found socio-cultural factors moderated engagement with HIV services. These influences included community factors, positive and negative interactions with the health system if training of health workers had been conducted on MSM-specific issues; presence of a social support system for MSM and MSM knowledge of the services available, including Pre-exposure prophylaxis (PrEP).

\section{Importance of training and flexible work schedules}

Many participants, both MSM and health workers, recommended that some facilities remain open after standard working hours when HIV prevention services are often critical. In addition, participants mentioned the importance of training for both health workers and for the MSM community. Training topics that were cited as critical for health workers were gender diversity, customercare-especially focussing on confidentiality; promoting acceptance of MSM and how to support disclosure of sexual orientation.

...you wonder how a real health worker who knows that people have...feelings and also knows that the gays are there in society but because they are against them, they can betray the gays... I even wonder how the doctors who are medically trained could say that homosexuality is not there and that we don't even have feelings (FGD-MSM).

Some MSM participants mentioned that stigma and discrimination had diminished compared with 10 years ago when there were no health facilities where they felt comfortable.

Where an effort was made to train healthcare workers on gender diversity, many MSM found an accepting experience at those health facilities.
Because we now have MSM friendly clinics or what we would call LGBT friendly pharmacies... now we come freely and bend to show them the pain we are experiencing in our bottoms (FGD-MSM)

Health workers stated there were some strategies they have used to change current norms at the facility level including designing and delivering health talks to specifically explain the MSM friendly services at that facility.

We thought of different health talks in our normal clinics that they should tell them we work on different categories and if you are there and you feel uncomfortable please come and talk to these special people in the health centre. They will help you because we offer friendly services, we are not discriminative, we are non-judgmental. (FGD-HCP)

\section{Importance of relationships and community support}

Societal and cultural norms influence perceptions about MSM. Healthcare providers noted the limited understanding of MSM and the challenges with patient/ provider relationships.

I think there is a poor relationship between the health workers and these people. So, we need to create that relationship between us and them, so that they can come and be free when they are at our health centres (FGD-HCP).

Providers also highlighted that how trust between providers and patients is key to quality services. In addition, participants cited examples of coping with the support and strength of their community. If someone fell sick, he could call a community member who would come to help.

Healthcare workers discussed how integral the church is in Ugandan society and how rejection by the church can be a difficult dilemma for MSM. There was consensus in all the discussions that the church in Uganda does not accept homosexuality. Some MSM members noted that in other countries they could marry, but confirmed that they had never heard of a church in Uganda that condones same sex behaviour in general including marriage.

First of all, these people [MSM] go to church for counselling looking for someone that can help them out. They need that comfort and peace of mind. They cannot get it from church because religion condemns it. So, I don't even know any religion that accepts MSM. (FGD-HCP).

\section{Engagement in health services}

In discussing navigating healthcare in Kampala MSM mentioned there were individuals in particular facilities and specific departments who were trusted and approachable. Some facilities had MSM-friendly counsellors who were non-judgmental and provided appropriate services. Both healthcare providers and MSM confirmed the importance of the strategy of selecting an individual in the facility that can be a trusted liaison.

Not everywhere but there in the counselling department. ...the counselling department is where they allocated some counsellors whom we approach and they respond to our 
problems ... They don't disturb us as long as we tell them that we are MSM they just refer us to that special room and we are worked on very fast (FGD-MSM)

One participant mentioned a specific NGO that provided quality services.

Another MSM further explained that they may prearrange their visit to ensure that the specific contact person is on-site and available.

Those health facilities which have been mentioned have contact persons. When you want to go there you have to call first that contact person. You cannot just walk in and start telling any health worker you find there that I am a gay, I had sex and my behind is affected. The health workers in those facilities were trained. Because even those from Jinja and Entebbe come to this facility. (FGD-MSM)

\section{DISCUSSION}

In sub-Saharan Africa, though the environment has slowly changed in terms of tolerance around lesbian,gay, bisexual, transgender and intersex (LGBTI) issues over the last 5 years, MSM continue to be an understudied and underserved group, reflecting the criminalisation of MSM behaviour and socio-cultural, familial, self-stigmatisation and discrimination in both urban and rural environments. $^{2} 10203132$ We have described how social, psychological and structural factors moderated engagement in services.

\section{Stigma and policy}

Our findings from Kampala clearly demonstrate the strong influence of multilayered stigma at the individual, family, community and policy levels as an obstacle to effective HIV prevention and care services; both providers and patients shared this perspective. Findings from studies in other African countries (Kenya, Botswana, Namibia, Malawi, South Africa and Swaziland) show the disproportionate burden of HIV and the influence of stigma on health seeking behaviour. ${ }^{32-36}$ As has been discussed, since early in the HIV epidemic, stigmatisation of marginalised populations influences healthcare utilisation in a myriad of ways, including fear of seeking healthcare, lack of disclosure of same sex relationships to healthcare providers, denial of services related to one's sexuality. ${ }^{33} \mathrm{~A}$ global online survey of over 4000 participants evaluated the effect of the enforcement of laws criminalising homosexuality on access to services and found that arrests and convictions under laws applicable to being MSM had a strong negative association with use of HIV prevention and care services with the strongest effects in subSaharan Africa. ${ }^{26}$ HIV prevention and care services must be designed using a wide lens, with interventions that consider the cultural, social, legal and political circumstances that influence the changes in attitudes, discrimination and violence. Carefully crafted interventions that are multilayered and include structural components and a consideration for the family, community and healthcare context are of the utmost importance.

\section{Facilitators to health service access}

In Kenya, Graham and colleagues found that identifying providers and family or friends as well as engaging with trusted LGBTI organisations, assisted many men with accepting and disclosing their sexual identity. ${ }^{32}$ Our findings also highlighted the importance of providerpatient trust in health service utilisation and the role that training in gender diversity can have in building trusting relationships.

\section{Limitations}

This sample was chosen purposefully from the urban area of Kampala and therefore is not generalisable to all MSM or healthcare providers nor to rural areas in Uganda. However, these data do reflect experiences of participants from two groups (MSM and healthcare providers) and reflect varied experiences with navigating healthcare access as well as different providers of HIV care. As one of the few qualitative explorative studies of MSM and healthcare providers' view's, the study has important implications for the provision of HIV care and treatment of MSM in Kampala, where large numbers of MSM live in Uganda.

\section{Future areas of exploration for research and service}

Through both qualitative and quantitative studies as well as programme reports on capacity building, service delivery and community organisation, data have been amassed that paint a dim picture of the sexual health of MSM in Africa. A review conducted over 10 years ago of the prevalence of HIV among MSM in low- and middleincome countries noted that only four African countries had reliable estimates of HIV prevalence among MSM, with the prevalence among MSM significantly elevated over the general adult male population in all African countries with available data. ${ }^{3}$ In a separate study conducted by Baral, Beyrer and colleagues, the overall HIV prevalence among MSM in Botswana, Malawi and Namibia was $17.4 \%$ with an HIV prevalence of nearly $50 \%$ in MSM aged 30 to $49 .{ }^{37}$ The Baral study also proposed intervention ideas to inform appropriate prevention packages for MSM to address use of condoms and waterbased lubricants, and human rights violations related to their sexual orientation. ${ }^{37}$

To optimise the impact of individual-focussed interventions and mitigate the distinctive and dynamic risk environments faced by MSM in Africa, fostering safe environments where MSM can both disclose their sexual behaviour and seek appropriate health and HIV prevention services are core components in fighting the HIV epidemic in this marginalised community.

\section{Author affiliations}

${ }^{1}$ Global Health Sciences, University of California, San Francisco, San Francisco, California, USA

${ }^{2}$ School of Public Health, Makerere University College of Health Sciences, Kampala, Uganda

${ }^{3}$ Centers for Disease Control and Prevention, Uganda, Kampala, Uganda 
${ }^{4}$ Department of Medicare, Division of Infectious Diseases, Johns Hopkins School of Medicine, Baltimore, Maryland, USA

${ }^{5}$ National Institute of Allergy and Infectious Diseases Division of Intramural Research, Bethesda, Maryland, USA

${ }^{6}$ Department of Epidemiology, Rollins School of Public Health, Atlanta, Georgia, USA ${ }^{7}$ Centers for Disease Control and Prevention, Atlanta, Georgia, USA

Acknowledgements The authors are grateful to study participants, study staff and reviewers.

Contributors WH, SJR, PS designed the study with MO. RLK, RA, GA, ZS conducted data analysis. RLK wrote the manuscript. All authors edited and read the final manuscript.

Funding This project has been supported by the National Institute of Allergy and Infectious Diseases (grant R01Al1094575) and in part by the Division of Intramural Research, National Institute of Allergy and Infectious Diseases, National Institutes of Health and in part by the President's Emergency Plan for AIDS Relief (PEPFAR) through the Centers for Disease Control and Prevention under the terms of cooperative agreement 5U2GPS000971.

Disclaimer The findings and conclusions in this report are those of the authors and do not necessarily represent the official position of the funding agencies.

Competing interests None declared.

Patient and public involvement Patients and/or the public were involved in the design, or conduct, or reporting or dissemination plans of this research. Refer to the Methods section for further details.

Patient consent for publication Not required.

Provenance and peer review Not commissioned; externally peer reviewed.

Data availability statement All data relevant to the study are included in the article or uploaded as supplementary information.

Open access This is an open access article distributed in accordance with the Creative Commons Attribution Non Commercial (CC BY-NC 4.0) license, which permits others to distribute, remix, adapt, build upon this work non-commercially, and license their derivative works on different terms, provided the original work is properly cited, appropriate credit is given, any changes made indicated, and the use is non-commercial. See: http://creativecommons.org/licenses/by-nc/4.0/.

ORCID iD

Rachel King http://orcid.org/0000-0002-0085-3498

\section{REFERENCES}

1 King R, Barker J, Nakayiwa S, et al. Men at risk; a qualitative study on HIV risk, gender identity and violence among men who have sex with men who report high risk behavior in Kampala, Uganda. PLoS One 2013;8:e82937.

2 Okall DO, Ondenge K, Nyambura M, et al. Men who have sex with men in Kisumu, Kenya: comfort in accessing health services and willingness to participate in HIV prevention studies. J Homosex 2014:61:1712-26.

3 Baral S, Sifakis F, Cleghorn F, et al. Elevated risk for HIV infection among men who have sex with men in low- and middle-income countries 2000-2006: a systematic review. PLoS Med 2007;4:e339.

4 Daniels J, Maleke K, Lane T, et al. Learning to live with HIV in the rural Townships: a Photovoice study of men who have sex with men living with HIV in Mpumalanga, South Africa. J Assoc Nurses AIDS Care 2017;28:408-21.

5 Pilgrim N, Musheke M, Raymond HF, et al. Quality of care and HIV service utilization among key populations in Zambia: a qualitative comparative analysis among female sex workers, men who have sex with men and people who use drugs. AIDS Care 2019;31:460-4.

6 Senior K. HIV, human rights, and men who have sex with men. Lancet Infect Dis 2010;10:448-9.

7 McIntyre JA. The need for HIV prevention interventions for men who have sex with men in Africa. Sex Transm Infect 2010;86:82-3.

8 IGLHRC. Off the map: how HIV/AIDS programming is failing samesex practicing people in Africa; 2007.

9 Rispel LC, Metcalf CA. Breaking the silence: South African HIV policies and the needs of men who have sex with men. Reprod Health Matters 2009;17:133-42.

10 Beyrer C, Baral SD, Walker D, et al. The expanding epidemics of HIV type 1 among men who have sex with men in low- and middle-income countries: diversity and consistency. Epidemiol Rev 2010;32:mxq011:137-51.

11 Sanders EJ, Graham SM, Okuku HS, et al. HIV-1 infection in high risk men who have sex with men in Mombasa, Kenya. AIDS 2007;21:2513-20.

12 van Griensven F, Sanders EJ. Understanding HIV risks among men who have sex with men in Africa. Sex Transm Dis 2008;35:355-6.

13 Raymond HF, Kajubi P, Kamya MR, et al. Correlates of unprotected receptive anal intercourse among gay and bisexual men: Kampala, Uganda. AIDS Behav 2009;13:677-81.

14 Kajubi P, Kamya MR, Raymond HF, et al. Gay and bisexual men in Kampala, Uganda. AIDS Behav 2008;12:492-504.

15 Muraguri N, Temmerman M, Geibel S. A decade of research involving men who have sex with men in sub-Saharan Africa: current knowledge and future directions. Sahara J 2012;9:137-47.

16 Price MA, Rida W, Mwangome M, et al. Identifying at-risk populations in Kenya and South Africa: HIV incidence in cohorts of men who report sex with men, sex workers, and youth. J Acquir Immune Defic Syndr 2012;59:185-93.

17 Smith AD, Tapsoba P, Peshu N, et al. Men who have sex with men and HIV/AIDS in sub-Saharan Africa. Lancet 2009;374:416-22.

18 Knox J, Yi H, Reddy V, et al. The fallacy of intimacy: sexual risk behaviour and beliefs about trust and condom use among men who have sex with men in South Africa. Psychol Health Med 2010;15:660-71.

19 Larmarange J, Wade AS, Diop AK, et al. Men who have sex with men (MSM) and factors associated with not using a condom at last sexual intercourse with a man and with a woman in Senegal. PLoS One 2010;5:e13189.

20 Geibel S, Tun W, Tapsoba P, et al. HIV vulnerability of men who have sex with men in developing countries: horizons studies, 2001-2008. Arlington: Management Sciences for Health, 2010

21 Tucker A, Liht J, de Swardt G, et al. An exploration into the role of depression and self-efficacy on township men who have sex with men's ability to engage in safer sexual practices. AIDS Care 2013;25:1227-35.

22 Okal J, Luchters S, Geibel S, et al. Social context, sexual risk perceptions and stigma: HIV vulnerability among male sex workers in Mombasa, Kenya. Cult Health Sex 2009;11:911828488:811-26.

23 Lane T, Mogale T, Struthers H, et al. "They see you as a different thing": the experiences of men who have sex with men with healthcare workers in South African township communities. Sex Transm Infect 2008;84:430-3.

24 Jobson GA, Theron LB, Kaggwa JK, et al. Transgender in Africa: invisible, inaccessible, or ignored? SAHARA-J: Journal of Social Aspects of HIVIAIDS 2012;9:160-3.

25 Fay H, Baral SD, Trapence G, et al. Stigma, health care access, and HIV knowledge among men who have sex with men in Malawi, Namibia, and Botswana. AIDS Behav 2010.

26 Santos G-M, Makofane K, Arreola S, et al. Reductions in access to HIV prevention and care services are associated with arrest and convictions in a global survey of men who have sex with men. Sex Transm Infect 2017;93:62-4

27 Hladik W, Barker J, Ssenkusu JM, et al. Hiv infection among men who have sex with men in Kampala, Uganda-A Respondent driven sampling survey. PLoS One 2012;7:e38143.

28 Hladik W, Sande E, Berry M, et al. Men who have sex with men in Kampala, Uganda: results from a Bio-Behavioral Respondent driven sampling survey. AIDS Behav 2017;21:1478-90.

29 Creswell J. Qualitative inquiry \& research design: choosing among five approaches. 2nd edn. Thousand Oaks: SAGE publications, 2007.

30 Boyatzis R. Transforming qualitative information: thematic analysis and code development. SAGE Publications, Inc, 1998.

31 Maleke K, Makhakhe N, Peters RP, et al. HIV risk and prevention among men who have sex with men in rural South Africa. Afr J AIDS Res 2017;16:31-8.

32 Graham SM, Micheni M, Secor A, et al. HIV care engagement and ART adherence among Kenyan gay, bisexual, and other men who have sex with men: a multi-level model informed by qualitative research. AIDS Care 2018;30:S97-105.

33 Maleke K, Daniels J, Lane T, et al. How social stigma sustains the HIV treatment gap for MSM in Mpumalanga, South Africa. Glob Health Promot 2019;26:6-13.

34 Stahlman S, Sanchez TH, Sullivan PS, et al. The prevalence of sexual behavior stigma affecting gay men and other men who have sex with men across sub-Saharan Africa and in the United States. JMIR Public Health Surveill 2016;2:e35.

35 Risher K, Adams D, Sithole B, et al. Sexual stigma and discrimination as barriers to seeking appropriate healthcare among men who have sex with men in Swaziland. J Int AIDS Soc 2013;16:18715. 
36 Fay H, Baral SD, Trapence G, et al. Stigma, health care access, and HIV knowledge among men who have sex with men in Malawi, Namibia, and Botswana. AIDS Behav 2011;15:1088-97.
37 Baral S, Trapence G, Motimedi F, et al. HIV prevalence, risks for HIV infection, and human rights among men who have sex with men (MSM) in Malawi, Namibia, and Botswana. PLoS One 2009;4:e4997. 